\title{
Biomechanical and osteopathic approach to shoulder pain
}

\author{
STEPHEN GOLDMAN, DO
}

\begin{abstract}
One of the most common complaints heard by primary care physicians is shoulder pain. Yet, most shoulder discomfort can be attributed to a variety of physiologic and anatomic dysfunctions outside of the glenohumeral joint. This paper addresses the anatomic and biomechanical mechanisms of shoulder motion and presents a logical approach to diagnosis and osteopathic treatment of the sore shoulder.
\end{abstract}

Shoulder pain patients often present with nonspecific, diffuse discomfort in the proximal upper extremity. Frequently, the search for derangement of the glenohumeral joint is nonproductive, thus leading to ineffective treatment and a cycle of temporary relief followed by an acute exacerbation of pain.

The etiology of the pain frequently will be found in sites distant from the shoulder region, and definitive diagnosis requires an understanding of the anatomy and biomechanics of the upper extremity. In this paper, I describe how alterations in normal mechanics result in shoulder pain.

\section{Structure and function}

The relatively free-swinging, mobile shoulder girdle consists of a series of five joints and two articulations (Table 1) which allow maximum motion of the upper extremity. ${ }^{1}$ Restriction of motion at any of these seven sites will result in decreased motion of the upper extremity.

Such restrictions may represent primary disease of the skeleton, such as the arthritides or dysfunctional mechanical relationships. Successful treatment of shoulder dysfunction involves normalization of dysfunctional motion at all of the seven sites.

\begin{abstract}
Musculature
The intricate musculature of the shoulder girdle adds to the complexity of upper extremity motion. A total of eight functional groups effect motion in the scapula and humerus (Table 2). ${ }^{2,3}$ The musculature must accomplish a complex task in maximizing motion while maintaining stability in the glenohumeral joint. In addition, effective motion depends on normal function of each muscle within each group, because dysfunction of any one muscle or muscle group will result in decreased upper extremity motion.

A common misconception is that humeral abduction is initiated by the supraspinatus. However, the complex interrelationships among the muscles, joints, and articulations require that each muscle in the shoulder girdle contributes to humeral abduction. ${ }^{4}$
\end{abstract}

\section{Mechanisms of motion}

A discussion of motion mechanics requires a review of the concepts of mechanical structure and function ${ }^{5}$ : A link is defined as any single part of rigidly linked components that is rigidly attached to a base (frame) and has motion relative to all of the other components. A kinematic pair consists of any two links that remain in contact throughout motion. A closed mechanism exists when the last link in a movement is reconnected back to the frame; conversely, in an open mechanism, the last link is not reconnected.

Shoulder girdle motion provides a stable frame for upper extremity movement. The glenohumeral joint is an incongruous joint where asymmetric contact is made between the head of the humerus and the glenoid fossa; in any position, only one third of the humeral head lies in contact with the glenoid fossa. ${ }^{6}$ Thus, the musculature of the humerus 


\begin{tabular}{|c|c|}
\hline Structure & Description \\
\hline Sternoclavicular joint & $\begin{array}{l}\text { The only bony connection of } \\
\text { the upper limb to the } \\
\text { axial skeleton }\end{array}$ \\
\hline Acromioclavicular joint & $\begin{array}{l}\text { Consists of articulation } \\
\text { between the acromion } \\
\text { process of the scapula } \\
\text { and the distal end of the } \\
\text { clavicle }\end{array}$ \\
\hline Suprahumeral articulation & $\begin{array}{l}\text { Composed of the coracoid } \\
\text { and acromion processes } \\
\text { and coracoacromial } \\
\text { ligament; serves to pre- } \\
\text { vent upward dislocation } \\
\text { of the humerus and pro- } \\
\text { tects from downward blows } \\
\text { to the glenohumeral } \\
\text { joint and the head of the } \\
\text { humerus }\end{array}$ \\
\hline Scapulothoracic articulation & $\begin{array}{l}\text { This pseudojoint consists of } \\
\text { the gliding motion of the } \\
\text { scapula over the under- } \\
\text { lying rib cage }\end{array}$ \\
\hline Glenohumeral joint & $\begin{array}{l}\text { Involves the articulation of } \\
\text { the humerus and the } \\
\text { concave glenoid fossa }\end{array}$ \\
\hline First rib & $\begin{array}{l}\text { Has two joints - at the } \\
\text { transverse process of T-1 } \\
\text { and at the manubrium }\end{array}$ \\
\hline
\end{tabular}

and scapula must align the two surfaces to provide a maximal surface for motion at the glenohumeral joint. ${ }^{5}$ Limitations on these motions are determined by the bony construction of the shoulder girdle, as well as by ligamentous attachments of the bony articulations of the shoulder girdle.

Two separate but inherently similar mechanisms of shoulder motion have been described by Inman and associates ${ }^{4}$ and by Dvir and Berme. ${ }^{5}$ The findings of these authors reinforce several concepts of shoulder motion: (1) The upper extremity provides a downward, subluxating force on the shoulder girdle: (2) an upward force is necessary to counteract this downward pull; and (3) both passive and active motions are involved in this counteractive force. Passive forces involve the antagonistic pull of the clavicle at the sternoclavicular and acromioclavicular joints. Active forces are involved via contraction of the trapezius. ${ }^{4}$

\section{First phase}

Upper extremity motion can be separated into four phases. The first is considered the "setting mechanism," when the medial border of the scapula is anchored by action of the rhomboid major, rhomboid minor, serratus anterior, levator scapulae, and

\begin{tabular}{|c|c|}
\hline Category & Muscles \\
\hline Abductors of humerus & $\begin{array}{l}\text { Deltoideus (middle fibers) } \\
\text { Supraspinatus }\end{array}$ \\
\hline Scapular adductors & $\begin{array}{l}\text { Rhomboid major } \\
\text { Rhomboid minor } \\
\text { Trapezius }\end{array}$ \\
\hline Scapular abductors & Serratus anterior \\
\hline $\begin{array}{l}\text { Depressors/rotators of } \\
\text { humerus }\end{array}$ & $\begin{array}{l}\text { Teres major (medial } \\
\text { rotation) } \\
\text { Pectoralis major (medial } \\
\quad \text { rotation) } \\
\text { Subscapularis (medial } \\
\quad \text { rotation) } \\
\text { Latissimus dorsi (medial } \\
\quad \text { rotation) } \\
\text { Anterior deltoid (medial } \\
\quad \text { rotation) } \\
\text { Infraspinatus (lateral } \\
\quad \text { rotation) } \\
\text { Teres minor (lateral } \\
\text { rotation) } \\
\text { Posterior deltoid (lateral } \\
\text { rotation }\end{array}$ \\
\hline Scapular rotators & $\begin{array}{l}\text { Trapezius } \\
\text { Serratus anterior } \\
\text { Levator scapulae } \\
\text { Deltoid } \\
\text { Rhomboid major } \\
\text { Rhomboid minor }\end{array}$ \\
\hline Humeral adductors & $\begin{array}{l}\text { Pectoralis major } \\
\text { Latissimus dorsi } \\
\text { Teres major }\end{array}$ \\
\hline Humeral flexors & $\begin{array}{l}\text { Biceps brachii } \\
\text { Pectoralis major } \\
\text { Coracobrachialis } \\
\text { Anterior deltoid }\end{array}$ \\
\hline Humeral extensors & $\begin{array}{l}\text { Triceps brachii } \\
\text { Latissimus dorsi } \\
\text { Posterior deltoid } \\
\text { Teres major }\end{array}$ \\
\hline
\end{tabular}

the lower two sets of trapezius fibers. The setting mechanism involves relatively little motion of the scapula.

During abduction of the upper extremity, phase one abducts the arm from 0 to 30 degrees, which allows for maximal contact in the glenohumeral joint. Conversely, during flexion, phase one flexes the arm from 0 to 60 degrees, which results in increased incongruity in the glenohumeral joint. In either case, the shoulder is less stable than it is at rest. At the end of this phase, motion ceases because of limitations imposed by the coracoclavicular ligament.

\section{Second phase}

The second phase of motion occurs along a new mechanical link-the claviscapular link (Fig1) ${ }^{5}$. This link, which is formed by eliminating motion at the acromioclavicular joint, affords increased stability to the shoulder mechanism. At this point, a rotary axis exists around an imaginary line drawn from the sternoclavicular joint to a point on the proximal scapular spine. 


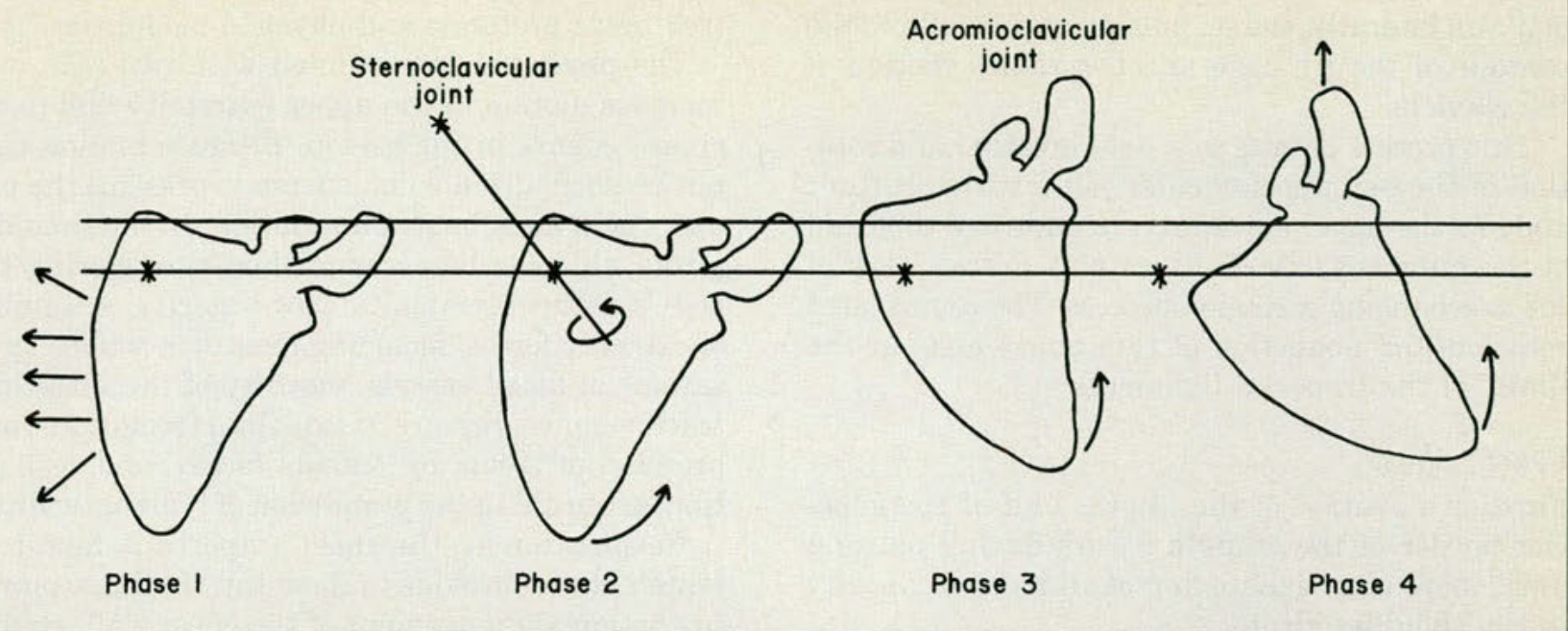

Fig 1. Phases of motion (adapted from Dvir and Berme ${ }^{5}$ ). Phase 1: Anchoring of medial scapular border, beginning of humoral abduction. Phase 2: Rotary motion along claviscapular link, beginning of scapular abduction, and further humoral abduction Phase 3: Rotation of clavicle along the long axis, further elevation of scapula, further humoral abduction. Phase 4: Manual elevation of scapula, maximal humoral abduction.

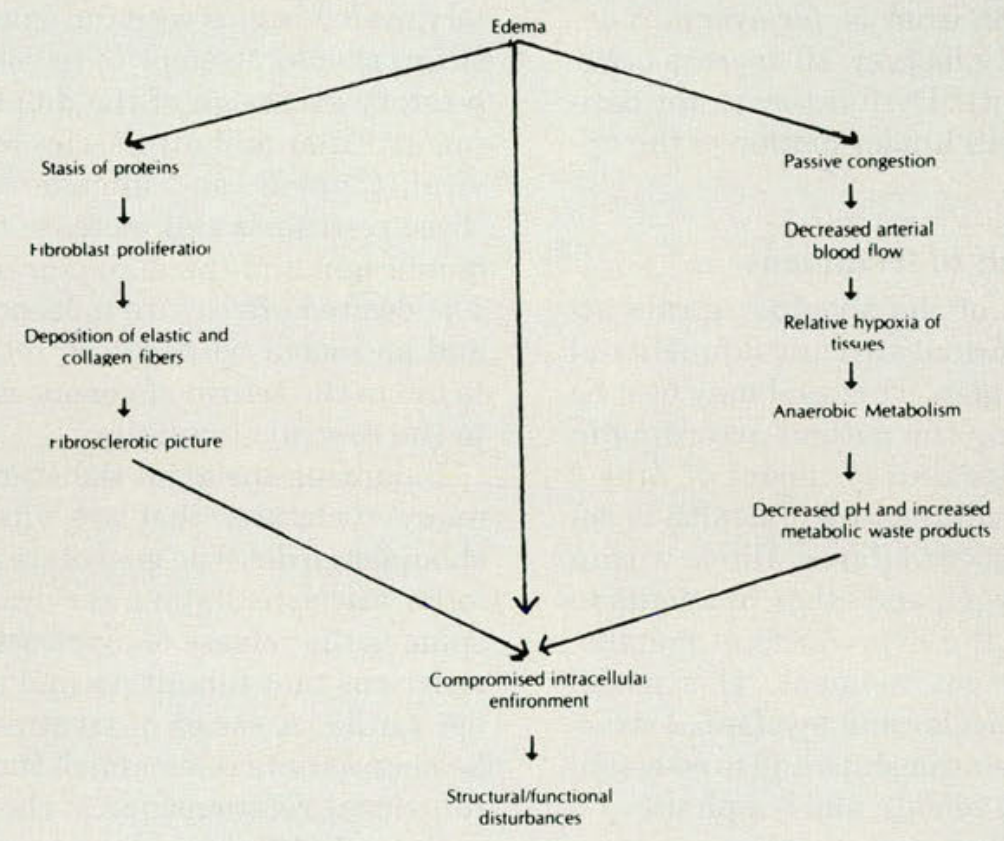

Motion occurs during this phase via contraction of the lower fibers of the serratus anterior and ceases at approximately 100 degrees of abduction because of tautness of the costoclavicular ligaments.

\section{Third phase}

Phase 3 begins with rotation of the clavicle along its long axis. Rotational movement now centers around the acromioclavicular joint. As the serra- 
tus anterior continues to pull the scapula inferiorly and laterally, the scapula passively follows the contour of the rib cage and the rotary motion of the clavicle.

This process results in a net elevation and rotation of the acromioclavicular joint, which further abducts the upper extremity. In addition, the head of the humerus externally rotates to free itself of the overhanging acromion process. The complicated rotation and abduction of this phase ends at the limits of the trapezial ligaments.

\section{Fourth phase}

Further elevation of the lateral half of the superior border of the scapula occurs during phase 4 until there is an exhaustion of all motion capacity in the shoulder girdle.

Three conclusions can be made concerning the motion dynamics of the upper extremity: (1) The initial phase of elevation is dependent upon the scapulothoracic articulation and the sternoclavicular joint; (2) further phases of elevation are dependent upon the glenohumeral and acromioclavicular joints; and (3) after the setting phase, every degree of scapular motion corresponds with 2 degrees of humeral motion (that is, for every 15 degrees of upper extremity motion, 10 degrees occur at the glenohumeral joint). ${ }^{7}$ Dysfunction in any component in the system will hinder motion of the upper extremity.

\section{Osteopathic approach to treatment}

Osteopathic treatment of the shoulder girdle attempts to restore the normal structural/functional relationships of that region. This goal may best be achieved by approaching the patient according to the respiratory and circulatory model of Zink. ${ }^{8}$ With this model, the maintenance of health is dependent upon the unimpeded flow of fluids within the body to provide oxygen and other nutrients to tissues and to remove the byproducts of metabolism from the cellular environment. This model seeks to re-establish articular and myofascial struc1 tural and functional relationships and to re-establish flow in the arterial, venous, and lymphatic systems.

Perhaps the most important of these fluid channels is the lymphatic system. According to Cathie and England, ${ }^{9}$ pathologic changes in the fluid dynamics of the venous and lymphatic systems result in passive congestion of tissues. In addition, lymphatic stasis is a well-recognized result of upper extremity dysfunction: ultimately it leads to tissue fibrosis (Fig 2). The resulting compromised intracellular environment renders tissues more sus- ceptible to injury and less amenable to conventional treatment protocols and physical modalities.

The physician is presented with two tasks-to increase motion in the upper extremity and to decrease edema in the region. Because motion cannot be normalized when edema is present, the primary goal must be its elimination. In the shoulder girdle, this can be accomplished by restoring the body's natural lymphatic flow capacity. A number of extrinsic forces, including muscular activity, pulsations of blood vessels, motility of the intestinal tract, venous pressure, tissue fluid formation, compression of tissue by outside forces, and respiration, act to aid in the propulsion of lymphatic fluid.

Respiration is the most important factor in lymph flow; it provides a constant, rhythmic pumping action via movement of the chest wall, changing tissue pressures, traction and relaxation of connective tissue elements, and movement of intercostal muscles. On inspiration, negative intrathoracic pressure draws lymphatic and venous fluid into the thorax. During exhalation, positive intrathoracic pressure propels lymphatic fluid through the thoracic duct into the central venous circulation. ${ }^{11}$

Treatment based on the respiratory and circulatory model ${ }^{8}$ begins with the axial skeleton. The physician should attempt to re-establish optimal respiratory excursion of the diaphragm by eliminating articular and myofascial restraints in the cervical, thoracic, and lumbar regions. Removal of these restraints will increase the excursion of the diaphragm and the diameter of the thoracic cage. The desired effects are a deeper inspiratory effort and an increased negative intrathoracic pressure to aid in the return of venous and lymphatic fluids to the central circulation.

Balancing the axial skeleton also will affect the many structures that are vital to motion in the shoulder girdle. The goal of treatment of the scapulothoracic articulation, cervical spine, and lumbar spine is the release of myofascial and articular restrictions that inhibit normal motion of the shoulder girdle. A series of treatments, however, may be necessary to re-establish the normal structural/ functional relationships of the axial skeleton.

Special attention also must be directed toward the thoracic inlet, first rib and the upper costal mechanics. ${ }^{12}$ The thoracic duct collects lymphatic fluid from the entire body except the right upper quadrant. The right lymphatic duct drains the right side of the head and neck, right arm, and parts of the right thorax. Both of these structures course upward underneath the first rib.

Re-establishing adequate costal mechanics will increase the negative intrathoracic pressure dur- 
ing inspiration and will increase the relative compressive effects of overlying tissues on these structures. Correction of first rib mechanics is also important in re-establishing motion at two of the articulatory links of the shoulder girdle.

Clavicular motion is an important area of examination and treatment, because impaired motion in this structure will inhibit phases 2 and 3 of shoulder girdle motion. Restriction of clavicular motion also will impair motion of the upper costal cage. Both articular links of the clavicle should be examined for restriction of motion, and, if possible, they should be freed from structural dysfunction.

Treatment of this structure would involve the acromioclavicular and sternoclavicular joints as well as releasing the clavicle from fascial restrictions caused by altered upper costal mechanics. Once the respiratory pump and clavicular motion are improved, attention should be turned to the glenohumeral region and the proximal part of the upper extremity. Various techniques may be used to facilitate lymphatic and venous drainage from this area. ${ }^{13,14}$

Physical therapy also plays an important role in re-establishing motion in the upper extremity. Passive and active range of motion, free weights, and ultrasound therapy are important modalities. Strict patient compliance to such a program is mandatory, because it may require several weeks to months to accomplish improved motion.

Even with a comprehensive program of osteopathic treatment and physical therapy, factors such as the age of the patient, stamina, and underlying pathologic conditions may prevent the patient from restoring full motion in the upper extremity.

The main goal of treatment, however, is to provide patients with a functional extremity that will enable them to accomplish daily tasks and activities.

\section{Summary}

Evaluation and treatment of shoulder pain must include consideration of the complex anatomic and mechanical functions of the upper extremity. Evaluation should cover the potential causes of shoulder pain originating outside the glenohumeral joint. Treatment based upon the principles of the respiratory and circulatory model $^{8}$ recognizes these complexities. When used in conjunction with a physical therapy program, this model re-establishes functional upper extremity mechanics.

1. Cailliet R:Shoulder pain, ed 2. Philadelphia, F.A. Davis Co, 1981.

2. Hoppenfeld S:Physical Examination of the Spine and Extremities. New York, Appleton-Century-Crofts, 1976.

3. Warfel:The Extremities. Philadelphia, Lea \& Febiger, 1974.

4. Inman VI, Saunders JB, Abbott LC: Observations on the function of the shoulder joint. J Bone Joint Surg 1944;26:1-30.

5. Dvir Z, Berme N: The shoulder complex in elevation of the arm: A mechanism approach. J Biomech 1978;11:219-225.

6. The applied anatomy of the shoulder and elbow. AAO Yearbook 1974;151-156.

7. Lehmkuhl L, Smith L: Brunnstrom's Clinical Kinesiology, ed 4. Philadelphia, F.A. Davis Co, 1983.

8. Zink JG: Respiratory and circulatory care: The conceptual model. $O s$ teopath Ann 1977;5:108-112.

9. Cathie AG, England RW, eds: The clinical importance of fascia. AAO Yearbook 1968;87-103.

10. Goldman S, Newgent E, Igram C: The model of respiratory and circulatory care. Osteopath Ann 1983;11:57-67.

11. Schad H, Flowaczny H, Brechtelsbauer $\mathrm{H}$, et al: The significance of respiration for thoracic duct flow in relation to other driving forces of lymph flow. Pflugers Arch 1978;378:121-125.

12. England RW: The first rib: Some clinical and practical considerations. JAOA 1961;89-101 (Oct):61

13. Zink JG, Lawson WB: The role of pectoral traction in the treatment of lymphatic flow disturbances. Osteopath Ann 1978;6:52-59.

14. Zink JG, Fetchik WD, Lawson WB: The posterior axillary folds: A gateway for osteopathic treatment of the upper extremities. Osteopath Ann 1981;9:81-88.

From the Department of General Practice, Botsford General Hospital, Farmington Hills, Mich.

Reprint requests to Dr Goldman, 22639 Glen Court, Farmington Hills, MI 48024. 